\title{
AS "EXTERNALIDADES" NO MEIO AMBIENTE DECORRENTES DO PROCESSO PRODUTIVO A LUZ DO PRINCÍPIO DA REPARAÇÃO INTEGRAL
}

\section{THE "EXTERNALITIES" ENVIRONMENT ARISING OUT OF THE PRODUCTION PROCESS PURSUANT TO THE PRINCIPLE OF INTEGRAL REPAIR}

\author{
André Lima de Lima \\ Cyro Alexander De Azevedo Martiniano
}

\section{RESUMO}

Os recursos ambientais são diariamente utilizados no processo produtivos de inúmeros produtos colocados a disposição da população. A produção de produtos acaba por utilizar o meio ambiente e a gerar as chamadas externalidades ambientais, essas externalidades podem ser valoradas e assim, possibilitar a responsabilização cível em respeito ao princípio da reparação integral. O objetivo do presente trabalho é analisar a discussão quanto às externalidades ambientais e sua relação com o princípio da reparação integral. Sendo a metodologia utilizada na presente pesquisa a bibliográfica, com método indutivo e qualitativo, com o auxilio da doutrina e legislação.

Palavras-chave: Direito ambiental, Externalidades, Princípio da reparação integral

\begin{abstract}
Environmental resources are daily used in the production process of many products placed at the disposal of the population. The production of products use the environment and generate the so-called environmental externalities, such externalities can be valued and thus enable civil liability in respect to the principle of full responsibility. The objective of this study is to analyze the discussion about environmental externalities and their relationship with the principle of integral repair. Since the methodology used in this study, the literature, with inductive and qualitative method, with the help of doctrine and law.
\end{abstract}

Keywords: Environmental law, Externalities, Principle of integral repair 


\section{INTRODUÇÃO}

Durante anos a humanidade acreditou que os recursos naturais eram ilimitados e que a utilização da matéria-prima em larga escala geraria um crescimento econômico maior e consequentemente um grande desenvolvimento das nações.

Ocorre que nos dias atuais, é clara a limitação dos recursos naturais frente ao grande número de mercados consumidores no mundo. As políticas econômicas voltadas para o consumo, o grande aumento populacional e as desigualdades socioeconômicas entre as populações mundiais que utilizam e destroe $\mathrm{m}$ em larga escala as águas dos rios, as florestas, os animais, plantas, entre vários outros recursos ambientais no mundo.

Pela grande importância do meio ambiente para a man utenção da vida, o direito ao meio ambiente equilibrado passou a ser considerado um direito fundamental de terceira dimensão, passando a ser tutelada por v árias constituições no mundo.

No Brasil, a Constituição da República Federativa d o Brasil de 1988 estabeleceu em seu artigo 225, que todos tem o direito ao meio ambiente ecologicamente equilibrado. Passou assim a ter o meio ambiente, no Brasil, uma proteção expressa na Constituição Federal, dando à união, estados, distrito federal e municípios o dever de propiciar um meio ambiente ecologicamente equilibrado.

Apesar da proteção constitucional dada ao meio ambi ente, muitos danos ainda ocorrem pelo anseio de utilizar os recursos naturais pelas pessoas físicas e principalmente jurídicas que em muitos casos causam degradam de forma devastadora o meio ambiente, sendo em alguns casos irreversíveis. Importante evidenciar as chamadas externalidades causadas pelas atividades produtivas, que de algumas formas podem contribuir negativa ou positivamente para o meio ambiente.

Essas externalidades, quando negativas, degradam o meio ambiente, mesmo que essa degradação não seja evidente ou que não se ja legislada, razão pela qual devem compor as também as reparações cíveis do evento dan oso, para que se evidencie a aplicação do princípio da reparação integral.

O objetivo do presente trabalho é analisar a discussão quanto às externalidades ambientais e sua relação com o princípio da reparaç ão integral. Sendo a metodologia utilizada na presente pesquisa a bibliográfica, commétodo indutivo e qualitativo, com o auxilio da doutrina e legislação. 


\section{BREVES NOÇÕES SOBRE MEIO AMBIENTE E O DIREITO}

Segundo PAULO (2013, p.1077), descrevendo o art. 225 da Constituição Federal, "todos tem o direito ao meio ambiente ecologicamente equilibrado, bem de uso comum do povo e essencial à sadia qualidade de vida, impondo-se ao Poder Público e à coletividade o dever de defende-lo e preservá-lo para as presentes e futuras gerações."

O dispositivo constitucional é claro para expressar o direito de todos os humanos a um meio ambiente ecologicamente equilibrado e sendo um direito fundamental de terceira dimensão e de grande import ância não somente para os brasileiros como para a população mundial, já que o meio ambiente é um bem que gera benefícios para a humanidade e não apenas para um E stado.

O meio ambiente não é importante apenas para a economia ou para o bem estar social, trata-se de um bem essência para a vida humana. Os componentes ambientais naturais como o ar, a agua, as plantas e animais, são alguns dos fatores essenciais para a vida humana, já que todo o ser humano depende de oxigênio para respirar, água para beber, plantas e animais para a alimentação.

Diante da importância do meio ambiente existe ainda uma série de outros fatores importantes para o bem estar social e para o desenvolvimento humano de forma digna, daí a importância do meio ambiente histórico e cultural, da preservação de ecossistemas únicos no planeta, a proteção de anima is em extinção.

Segundo o professor José Afonso da Silva, (2013, p20). o meio ambiente é "a interação do conjunto de elementos naturais, artifi ciais e culturais que propiciem o desenvolvimento equilibrado da vida em todas as suas formas".

O ambiente artificial seria o espaço urbano constru ído dentre os quais estão as casas, edifícios, praças, áreas verdes, ruas, entre outras construções. O meio ambiente cultural, este possui sua construção dentro de um a mbiente artificial, mas sua peculiaridade é o seu valor especial adquirido.

E como terceiro aspecto, e que é o centro principal da pesquisa, o Meio Ambiente Natural, que envolve rios, oceano, solo, o ar atmosférico, e que possui conceituação legislativa no art. 3, I, da lei 6.938 de 1981, in verbis:

Art $3^{\circ}$ - Para os fins previstos nesta Lei, entende-se por: I - meio ambiente, o conjunto de condições, leis, i nfluências e interações de ordem física, química e biológica, que permite, abr iga e rege a vida em todas as suas formas. 
Diante dos aspectos do meio ambiente, as analises valorativas são de grande importância para que dentro da seara do direito sej a possível a atuação dos tribunais nas decisões e direcionamento das legislações.

\section{PRINCÍPIO DA REPARAÇÃO INTEGRAL DO DANO AMBIENTA L}

O "princípio" é a caracterização do início ou da ba se de determinado pensamento, para o direito, os princípios possuem uma importância que podem determinar os rumos de uma determinada sociedade de direito, e segundo MACHADO (2015, p.53), "'Princípio" é, aqui, utilizado comoalicerce ou fundamento do Direito."

Conforme os vários conceitos observados sobre os princípios, SILVA apud Celso Antônio Bandeira de Mello (2015, p.57), apres enta a importância desse conceito e afirma que:

\footnotetext{
Princípio, já averbamos alhures, é, por definição,mandamento nuclear de um sistema, verdadeiro alicerce dele, disposição funda mental que se irradia sobre diferentes normas compondo-lhes o espírito e servindo de critério para sua exata compreensão e inteligência, exatamente por definir a lógica e a racionalidade do sistema normativo, no que lhe confere a tônica e lhe dá sentido humano. É o conhecimento dos princípios que preside a intelecção das diferentes partes componentes do todo unitárioque há por nome sistema jurídico positivo.
}

CAMARGO (2013, p.31) afirma ainda que: "Os princípios de direito são diretrizes, alicerces de valor genérico que embasam, condicionam e orientam o ordenamento jurídico, ou seja, são o seu fundamento ."

Com o constitucionalismo moderno, os princípios passaram a ter um protagonismo doutrinário e jurisprudencial, $\operatorname{PADILHA(2010,p.238),~em~suas~palavras~}$ destaca que "Dessa forma, no constitucionalismo moderno a norma jurídica é elevada a categoria de gênero, da qual são espécies o princípio e a regra, consolidando-se, desse modo, a plena normatividade dos princípios, de acordo com a nova hermenêutica constitucional."

A principiologia do direito com a sua evolução, pos sui uma aplicabilidade não apenas como aspecto informativo dentro de uma concepção positivista, mas os princípios passaram a ter uma aplicação direta, sen do utilizada como norma jurídica. $\mathrm{E}$ a adoção principiológica é adotada em cada caso concr eto e que direciona a atividade legislativa, conforme FARIAS (2014, p.48): 


\begin{abstract}
A grande força dos princípios provém de sua capacidade de investigar as fontes primárias de criação dos modelos jurídicos. Por meio de normas principiológica, o aplicador do direito alcança as concretas situações da vida e reflete em suas decisões a consciência jurídica vigente em determinada cultura. A resposta do legislador vem sempre a reboque, como forma de generalização das soluções que topicamente a socied ade já alcançou por intermédio do seu mandatário, o magistrado.
\end{abstract}

No campo ambiental, os princípios possuem uma grande importância na responsabilidade cível ambiental. Com a observação da necessidade da responsabilização para os produtores de danos ambie ntais, a própria Constituição Federal de forma expressa prevê a chamada "trípliceresponsabilização do poluidor" como apresentado por PADILHA (2010, p.276), conforme prevê o art. 225, $\S 3^{\circ}$ da $\mathrm{CF}$ :

As condutas e atividades consideradas lesivas ao meio ambiente sujeitarão os infratores, pessoas físicas ou jurídicas, a sanções penais e administrativas, independentemente da obrigação de reparar os danos causados.

A constituição federal prevê que o poluidor responderá nas esferas administrativa, penal e cível, evitando-se assim quaisquer construções doutrinárias quanto a uma possível condenação em alguma esfera q ue pudesse extinguir condenação em outra. A Lei de Política Nacional do Meio Ambiente responsabiliza as pessoas físicas e jurídicas em seu art. $14, \S 1^{\circ}$, in verbis:

Art 14 - Sem prejuízo das penalidades definidas pela legislação federal, estadual e municipal, o não cumprimento das medidas necessárias à preservação ou correção dos inconvenientes e danos causados pela degradação da qualidade ambiental sujeitará os transgressores: $\S 1^{\circ}$ - Sem obstar a aplicação das penalidades previ stas neste artigo, é o poluidor obrigado, independentemente da existênciade culpa, a indenizar ou reparar os danos causados ao meio ambiente e a terceiros, afetados por sua atividade. O Ministério Público da União e dos Estados terá legitimidade para propor ação de responsabilidade civil e criminal, p or danos causados ao meio ambiente.

Conforme PADILHA (2010, p.277), "A seriedade e gravidade da degradação ambiental exigem uma resposta jurídica pronta e eficaz, por meio de um sistema amplo de responsabilização do poluidor: trata-se do cumpr imento do 
"Princípio da Responsabilização Integral"." A reparação do dano a mbiental também possui previsão na Declaração do Rio de Janeiro de 1992, que aprese nta em seu Princípio 13:

Os Estados deverão desenvolver a legislação naciona 1 relativa à responsabilidade e à indenização referente às vítim as da contaminação e outros danos ambientais. Os Estados deverão coopera $r$ de maneira diligente e mais decidida no preparo de novas leis internacionais sobre responsabilidade e indenização pelos efeitos adversos dos danos ambi entais causados pelas atividades realizadas dentro de sua jurisdição, ou sob seu controle, em zonas situadas fora de sua jurisdição .

Apesar de a legislação conter as responsabilidades por danos causados, a própria legislação não contempla os diversos impact os ambientais que podem ser gerados com a degradação ambiental, exemplificando um caso concreto de que a condenação de um poluidor não contemplou todos os d anos ambientais causados, como cita MACHADO (2015, p.120):

No derramamento de 230.000t oriundo do naufrágio donavio AmocoCadiz, nas costas da Bretanha (França), em 1976, a empresa norteamericana Amoco foi condenada, por um Tribunal americano, a pagar as despesas de restauração do litoral e dos portos, as despesas da Administração Pública, mas os danos ocorridos com a biomassa não foram ind enizados.

Os danos evidenciados no exemplo anterior expõe a ineficácia da condenação imposta, por não abarcar a integralidade dos danos causados e dentro desse ponto que se mostra a importância de valorar o recurso ambiental degradado com a finalidade de se obter a responsabilização integral do bem. Segundo GRANZIERA (2009, p.29),

\footnotetext{
Havendo degradação ambiental ou poluição, isso é, d esequilíbrio no "conjunto de condições, leis, influencias e interaç ões de ordem física, química e biológica, que permite, abriga e rege a $\mathrm{v}$ ida em todas as suas formas", seu autor fica obrigado a reparar o dano ocorrido, pois não se admite que a degradação ambiental permaneça no ambiente.
}

As dificuldades de quantificar os danos não devem ser barreiras para a condenação dos danos, principalmente quanto aos dan os difusos e coletivos, 
FARIAS (2014, p.63) abordando o Enunciado 456 do Conselho de Justiça Federal, informa que:

\begin{abstract}
(...) a reparação integral se engrandece, em uma vi são prospectiva, como bem evidencia o Enunciado $\mathrm{n}^{\circ} 456$ do Conselho de Justiça Federal, "a expressão 'dano' no artigo 944 abrange não só os danos indivi duais, materiais ou imateriais, mas também os danos sociais, difusos, coletivos e individuais homogêneos". Isto significa que a dificuldade de quantificação não será barreira para que se implemente uma sanção reparató ria que se aproxime na medida do possível dos danos, mesmo que estes possuam natureza metaindividual e que seja necessário somar indenização in natura uma condenação pecuniária, para que se alcance a reparação integral.
\end{abstract}

Importante ainda a o estudo do Valor econômico dos recursos ambientais, para MOTTA (1997, p. 11) "o valor econômico dos recursos ambientais é derivado de todos

os seus atributos e, segundo, que estes atributos podem estar ou não associados a um uso. Ou seja, o consumo de um recurso ambiental se realiza via uso e não-uso."

Com a atribuição do uso e não-uso do recurso ambien tal, chega-se a seguinte expressão: VERA $=(\mathrm{VUD}+\mathrm{VUI}+\mathrm{VO})+\mathrm{VE}$.

Decompondo a expressão do VERA chega-se as seguinte variáveis utilizadas para a obtenção do valor de um determinado recurso ambiental. O valor de uso direto (VUD) é determinado pela contribuição direta que um recurso natural realiza em um processo de produção e consumo. Exemplos: Extração, visitação ou outra atividade de produção ou consumo direto;

O valor de uso indireto (VUI) inclui os benefícios derivados basicamente dos serviços que o ambiente proporciona para suportar o processo de produção e consumo. Exemplo: a proteção do solo feito pela vegetação e a estabilidade climática decorrente da preservação das florestas;

O valor de opção (VO) é baseado em quanto os indiví duos estão dispostos a pagar pela opção de preservar um bem para uso pesso al direto ou indireto no futuro, simplesmente para evitar o risco de não tê-lo no futuro. Exemplo: o benefício advindo de fármacos desenvolvidos com base em propriedadesmedicinais ainda não descobertas de plantas em florestas tropicais. Seria basicamente um investimento realizado pelas gerações presentes para as futuras. 
Os valores de existência (VE), de acordo com $\operatorname{MOTTA}(1997$, p. 12), não

são associados ao uso atual ou futuro, na verdade refletem questões morais,

culturais, éticas ou altruísticas. E como exemplo dessa variável temse- a mobilização

para salvamento de espécies em extinção.

Sendo essa nomenclatura VERA a ser utilizada na reparação integral dos danos como se observou.

A jurisprudência do Superior Tribunal de Justiça fundamenta suas decisões no princípio da reparação integral do dano ambiental e m seu informativo 0526:

\section{DIREITO PROCESSUAL CIVIL E AMBIENTAL. CUMULAÇÃO DAS OBRIGAÇÕES DE RECOMPOSIÇÃO DO MEIO AMBIENTE E DE COMPENSAÇÃO POR DANO MORAL COLETIVO.}

Na hipótese de ação civil pública proposta em razão de dano ambiental, é possível que a sentença condenatória imponha ao res ponsável,

umulativamente, as obrigações de recompor o meio a mbiente degradado e de pagar quantia em dinheiro a título de compensaçã o por dano moral coletivo. Isso porque vigora em nosso sistema jurídico o princípio da reparação integral do dano ambiental, que, ao deter minar a responsabilização do agente por todos os efeitos decorrentes da conduta lesiva, permite a cumulação de obrigações de fazer, de não fazer e de indenizar. Ademais, deve-se destacar que, embora o art. $3^{\circ}$ da Lei 7.347/1985 disponha que "a ação civil poderá ter por objeto a condenação em di nheiro ou o cumprimento de obrigação de fazer ou não fazer", é certo que a conjunção "ou" - contida na citada norma, bem como nos arts. $4^{\circ}$, VII, e 14 , § $1^{\circ}$, da Lei 6.938/1981 opera com valor aditivo, não introduzindo, portanto, alternativa excludente. Em primeiro lugar, porque vedar a cumulação desses remédios limitaria, de forma indesejada, a Ação Civil Pública - importante instrumento de persecução da responsabilidade civil de danos causa dos ao meio ambiente -, inviabilizando, por exemplo, condenações em danos m orais coletivos. Em segundo lugar, porque incumbe ao juiz, diante das normas de Direito Ambiental - recheadas que são de conteúdo ético intergeracional atrelado às presentes e futuras gerações -, levar em conta o comando do art. $5^{\circ}$ da LINDB, segundo o qual, ao se aplicar a lei, deve-se atender "aos fins sociais a que ela se dirige e às exigências do bem comum", cujo corolário é a constatação de que, em caso de dúvida ou outra anom alia técnico-redacional, a norma ambiental demanda interpretação e integraçã o de acordo com o princípio hermenêuticoin dubio pro natura, haja vista que toda a legislação de amparo dos sujeitos vulneráveis e dos interesses difusos e coletivos há sempre de ser compreendida da maneira que thes seja mais proveitosa e melhor possa viabilizar, na perspectiva dos resultados práticos, a prestação jurisdicional e a ratio essendi da norma. Por fim, a interpretação sistemática das normas e princípios ambientais leva à conclusão de que, se o bem ambiental lesado for imediata e completamente restaurado, isto é, restabelecido à condição original, não há falar, co mo regra, em indenização. Contudo, a possibilidade técnica, no futuro, de restauração in natura nem sempre se mostra suficiente para reverter ou recompor integralmente, no âmbito da responsabilidade civil, as várias dimensões do dano ambiental causado; por isso não exaure os deveres associados aos princípios do poluidor-pagador e da reparação integral do dano. $\mathrm{C}$ umpre ressaltar que o 
dano ambiental é multifacetário (ética, temporal, cológicae e patrimonialmente falando, sensível ainda à diversid ade do vasto universo de vítimas, que vão do indivíduo isolado à coletividad e, às gerações futuras e aos processos ecológicos em si mesmos considerados) . Em suma, equivocase, jurídica e metodologicamente, quem confunde prioridade da recuperação in natura do bem degradado com impossibilidade de cumulação simultânea dos deveres de repristinação natural (obrigação de fazer), compensação ambiental e indenização em dinheiro (obrigação de d ar), e abstenção de uso e nova lesão (obrigação de não fazer). REsp 1.328.753 -MG, Rel. Min. Herman Benjamin, julgado em 28/5/2013.

O princípio da reparação integral do dano deve ser aplicado para que se evite a destruição e a utilização completa do meio ambiente sem que os beneficiários dos recursos ou os causadores de danos não respondam de forma de forma efetiva da real destruição do meio ambiente.

\section{DAS EXTERNALIDADES AMBIENTAIS}

As externalidades são falhas de mercado de grande i mportância na economia ambiental e nos estudos dos recursos naturais. Segundo RIVAS (2014, p.61), o conceito

das externalidades é: "custos ou benefícios secundários, de consequência involuntárias, ou involuntários efeitos colaterais (benefícios ouprejudiciais) associados às transações de mercado." Ainda dentro da conceituação das exter nalidades, DERANI (2007, p.57) conclui que as externalidades são: "falhas de merca do nas quais efeitos de determinada atividade atingem terceiros (externos) nela não env olvidos."

MOTTA (1998, p.197) ainda conceitua as externalidades como princípio microeconômico como segue: "Bens públicos e externalidades: na qual analisam-se as imperfeições do mercado em definir apropriadamente os direitos de propriedade que

determinam o padrão de uso e distribuição dos recur sos e sua contribuição para o bemestar social." Assim, liga-se a utilização dos bens e suas contribuições para a sociedade. Diante do processo produtivo, as externalidades podem ser observadas, no

momento em que o setor produtivo utiliza-se do meio ambiente de forma gratuita, sendo que deveria pagar pelo seu uso ou pela sua poluição, mas pela inexistência de meios legais para a cobrança ou punição, os recursos natu rais são utilizados muitas vezes de forma indevida. 
A utilização do ar ou dos rios por alguma indústria que não paga pela fumaça que libera no ar e também não paga pelos seus dejetos lançados nos rios. Apesar de muitas vezes ser algo normal a utilização desses re cursos naturais para tais práticas, essas atitudes podem gerar externalidades como o aparecimento de chuva ácida ou a mortandade de peixes.

As externalidades podem ter efeitos positivos ou negativos, os quais segundo DERANI (2007, p.57): "positivos (a fabrica instala-se numa cidade pequena e gera maior movimentação econômica no local) ou negativos (a mesma fabrica polui o rio que margeia o município, tendo em vista não haver legis lação de proteção ambiental que a impeça de fazer isso)."

As externalidades positivas são benéficas e caracteriza-se na atuação de um agente acaba por externalizar benefícios para terceiros sem que esses paguem por esses benefícios, como exemplifica RIVAS (2014, p.61), "(...) quando proprietários de terras suburbanas geram benéficos privados pelo plantio de árvores, eles também geram benefícios sociais por reduzirem a erosão, aumentan do a qualidade do ar, reduzindo o aquecimento global e melhorando a estética da vizinhança."

Já as externalidades negativas devem ser computadase utilizadas como forma de responsabilizar os geradores dessas externalidades. Assim, observando a responsabilidade atribuída ao causador de danos ambientais, a valoração das externalidades se faz importante para a obtenção in tegral do prejuízo causado, tendo o instituto da responsabilidade objetiva como meio a ser adotado, conforme SIRVINSKAS (2003, p.36):

(...) o poluidor deverá arcar com o prejuízo causado ao meio ambiente da forma mais ampla possível. Impera em nosso sistema, a responsabilidade objetiva, ou seja, basta a comprovação do dano ao m eio ambiente, a autoria e o nexo causal, independentemente da existência da culpa.

As externalidades negativas devem ser internalizadas, ou seja, devem ser arcadas pelos seus produtores e não servirem de con sequências para terceiros, que segundo SILVA (2015, p.73),

Para a aplicação, os custos sociais externos que ac ompanham o processo produtivo ( $v . g$. valor econômico decorrentes de danos ambientais) $\mathrm{d}$ evem ser internalizados, ou seja, o custo resultante da poluição deve ser 
assumido pelos empreendedores de atividades potencialmente poluidoras, os custos de produção. Assim, o causador da poluição arcará com os custos necessários à diminuição, eliminação ou neutralização do dano amb iental.

Essas externalidades negativas são justamente o res ultado negativo da produção que é repassado para a sociedade de forma que o poluidor não paga por essa poluição, e dessa forma a sociedade é quem tem que arcar com essa poluição pela utilização gratuita de determinado recurso ambienta 1. De modo exemplificativo, poder-se-ia imaginar a utilização de rios por empresas qu ando as mesmas lançam alguns de seus dejetos de modo que a sociedade é que terá quesuportar com essa poluição, ou quando a fumaça da indústria é jogada no ar atmosférico, sendo que por mais que seja tolerável certa quantidade de poluentes lançados nomeio ambiente, quando se observa os dejetos de todas as indústrias, a poluição acaba prejudicando o ambiente, e é a sociedade que acaba arcando com os custos negativos dessa poluição.

Assim como apresenta PADILHA (2010, p.257) em sua abordagem das externalidades e internalização do custo ambiental:

\begin{abstract}
A produção de resíduos é decorrência das falhas domercado econômico. Tais falhas são denominadas "externalidades", pois geram prejuízos suportados por terceiros, alheios ao processo econô mico, em decorrência do uso de determinados recursos naturais. Nesse sentido, o objetivo do princípio do poluidor-pagador significa promover a "internalização" do custo ambiental, transformando a externalidade negativa, ou o custo social, num custo privado, pois não é possível admitir-se a socialização do prejuízo e a privatização dos lucros.
\end{abstract}

Quanto aos tipos de externalidades, existem as externalidades pecuniárias e externalidades tecnológicas, que podem ser distingu idas pelos efeitos diferenciais nos limites das possibilidades de produção.

Segundo RIVAS (2007, p. 64),

A combinação real de bens que são produzidos é dete rminada tanto pelo limite de possibilidades de produção quanto pelas $\mathrm{p}$ referencias do consumidor. O limite de possibilidades de produção determina o que é possível produzir, enquanto que as preferencias do consumidor determinam qual das possíveis combinações será realmente produzida. Por exemplo, se a combinação atual de algodão e aço deixa os consumid ores insatisfeitos, querendo mais algodão, o preço do algodão aumentará, porque os consumidores tentarão comprar mais algodão, o que e nsejara em mais produção de algodão e menos produção de aço. 
Visando a modificação da socialização do prejuízo $\mathrm{p}$ ara a privatização do prejuízo, é necessário que se tenha o valor dessasexternalidades, para a efetivação do princípio da reparação integral, impedindo que dano $\mathrm{s}$ decorrentes das externalidades negativas não sejam computadas nas reparações cívei s por danos ambientais. Dessa maneira, LEITE (2004, p.98) tem o seguinte posicionamento:

\begin{abstract}
Imputando aos custos de produção todas as externali dades ambientais, deverão ser produzidas objetivamente condições que não permitam que ao operador econômico seja mais vantajoso poluir do qu e implementar medidas de prevenção. Frise-se que essa orientação obedecer á naturalmente ao princípio democrático, restringindo a atuação do Estado na forma de atividade de repressão dos comportamentos ambiental mente proibidos.
\end{abstract}

Diante das externalidades, bem como das ações preve ntivas e repressivas contidas nas legislações a obtenção das externalida des negativas se faz necessária como forma de fundamento para a concretização não apena do principio da reparação integral como também do princípio do poluidor-pagador, tendo uma ligação íntima com a responsabilidade cível como bem afirma $\operatorname{SILVA~(2015,~p.~75):~}$

\footnotetext{
(...) dirigida ao poluidor para que assuma todas as consequências derivadas do dano ambiental. De acordo com esse entendimento, esse princípio se traduz na obrigação de reparar os danos e prejuízos, sendo inclusive denominado por alguns doutrinadores como "princípio da reparação" ou "princípio da responsabilidade"
}

Observa-se as externalidades negativas no campo ambiental como danos gerados aos terceiros e que devem ser contabilizados para que se a efetivação do principio da reparação integral.

A relação entre as externalidades e o princípio da reparação ambiental se faz quando observa-se que as externalidades negativas são produtoras de danos ambientais entretanto, esses danos apesar de existentes, não s ão contabilizados ou suportados pelos seus produtores. Enquanto que o princípio da reparação integral do dano ambiental, dispõe que todo o dano ambiental deve ser reparado, sendo que essa reparação deve ser integral. 
Dessa maneira, as externalidades devem ser computadas dentro das condenações ambientais caracterizadas na responsabi lidade cível por danos ambientais. Ocorre que em muitos casos, essas reparações não sã o adotadas por dificuldades de valoração ou pelo simples desconhecimento das exter nalidades produzidas.

Percebe-se no julgado a seguir a condenação de dete rminado produtor por produzir as chamadas externalidades negativas, observando-se que os tribunais já vem adotando tais medidas condenatórias tendo como base a principiologia do direito, sendo que no caso concreto, adotou-se o princípio do poluidor-pagador, como segue na decisão a seguir:

\footnotetext{
DIREITO AMBIENTAL. DANO AMBIENTAL. CORTE DE ÁRVORES NATIVAS EM ÁREA DE CONSERVAÇÃO. ART. 40, PARÁGRAFO $1^{\circ}$, C/C 70, DA LEI 9.605/98. CERCEAMENTO DE DEFESA. NÃO OCORRÊNCIA. APLICAÇÃO DE PENALIDADE POR SERVIDOR DO IBAMA. LEGITIMIDADE. EXERCÍCIO DO PODER DE POLÍCIA. RESPONSABILIDADE OBJETIVA. ART. 225, PARÁGRAFO $3^{\circ}$. PRINCÍPIO DA PREVENÇÃO E DO POLUIDOR-PAGADOR. APLICAÇÃO. (...) 3- A pena pecuniária é decorrente do princípio do poluidor-pagador, que obriga o causador do dano a suportar o ônus da produção das chamadas externalidades negativas. 4- A conduta amolda-se perfeitamente na prevista no art. 40, parágrafo $1^{\circ}$,c/c 70, da Lei 9.605/98 e, ainda que negue, alegando o desconhecimento do fato ou que não autorizou o corte das árvores pelos seus empregados, tem-se com razoável o entendimento de que o dano o beneficiou, pois, as madeiras extraídas estavam sendo utilizadas na construção de cerca na Fazenda Bananeiras de propriedade do apelante. (...) (2009, TRF-5 - AC: 411200 AL 001045276.2005.4.05.8000).
}

Com as externalidades, não apenas o princípio da re paração integral como outros princípios ambientais são em conjunto utiliz ados na aplicação da responsabilização civil.

Diante da própria caracterização condenatória das e xternalidades negativas, devem ser adotados mecanismos para se obter a as externalidades produtivas de vários processos produtivos de modo a não permitir o benef icio particular em detrimento do meio ambiente, destacando nas condenações o princíp io da reparação integral como forma de inibir a produção desenfreada com a produç ão de externalidades negativas advindas da produção, bem como para evitar a enriqu ecimento sem causa pela utilização dos recursos ambientais com a produção d e externalidades sem o seu devido pagamento. 


\section{CONSIDERAÇÕES FINAIS}

Em conformidade com o mandamento do direito fundamental descrito no art. 225 do Constituição Federal, o direito do povo por um $\mathrm{m}$ eio ambiente ecologicamente equilibrado, se tornou um dever do Estado. E partindo dessa premissa, a importância de se valorar os recursos ambientais.

Diante da existência das chamadas externalidades, videncia-se a ocorrência da danos no meio ambiente que são repassados a terceir os e não fazem parte do pagamento pelos reais causadores dos danos. Entretanto a legislação brasileira bem como as decisões judiciais vem no sentido de que devem as e xternalidades negativas serem suportadas pelos agentes causadores dessas falhas de mercado.

Realizando uma verificação de casos concretos e sit uações econômicas práticas é possível se verificar as consequências e a presença das externalidades negativas. Com as externalidades é possível determinar os danos levados à sociedade, gerando a condenação para os reais causadores dos ambientais e perseguindo o meio ambiente equilibrado conforme a Constituição da Republica Fe derativa do Brasil.

Assim com base no principio da reparação integral n o âmbito ambiental é possível perceber que as externalidades devem fazer parte da composição condenatória dos agentes produtivos que causam as externalidade negativas.

Razão pela qual é tão importante ter o conhecimentos das externalidades para a determinação de condenações judiciais, bem como par a se ter base na adoção de políticas públicas voltadas para o meio ambiente, na conservação dos seus valores e até mesmo na produção legislativa com a finalidade de $\mathrm{s}$ e evitar os danos ambientais. 


\section{REFERÊNCIAS}

BRASIL. Constituição da República Federativa do Brasil. Disponível em: http://www.planalto.gov.br/ccivil_03/constituicao/constituicaocompilado.htm acesso em: 12 jan 2014.

Política Nacional do Meio Ambiente. Lei 6.938/1981

de 31/08/1981. Disponível em: http://www.planalto.gov.br/ccivil_03/leis/16938.htm acesso em 12 jan. 2016.

CAMARGO, Thaísa Rodrigues Lustosa de., Sandro Nahmias Melo. Princípios de direito ambiental do trabalho. São Paulo: LTr, 2013.

DERANI, Cristiane. Daniel Antônio de Aquino Neto. Hileia: Revista de Direito Ambiental da Amazônia, ano 5, n.9. Valoraçã o Econômica dos Bens Ambientais, UEA Edições, 2007.

FARIAS, Cristiano Chaves de, Nelson Rosenvald, Felipe Peixoto Braga Netto. Curso de Direito Civil - Teoria da responsabilidade civil, responsabilidade civil em espécie.Volume 3. Editora Juspodivm, Salvador. 2014.

FIORILlO, Celso Antônio Pacheco. Curso de direito ambiental brasileiro. São Paulo: Saraiva, 2002.

GRANZIERA, Maria Luiza Machado. Direito Ambiental. São Paulo: Atlas, 2009.

JUSTIÇA, Superior Tribunal de. Informativo n. 0526. Período: 25 de setembro de 2013. Segunda Turma. Disponível em: http://www.jurisway.org.br/v2/bancojuris1 .asp?pagina $=1 \&$ idarea $=25 \&$ idmodelo $=34$ $\underline{388}$ acesso em 03/03/2016.

FEDERAL 5, Tribunal Regional - Apelação Cível: 411200 AL 0010452- 
76.2005.4.05.8000, Relator: Desembargador Federal José Baptista de Almeida Filho, Data de Julgamento: 15/09/2009, Quarta Turma, Data de Publicação: Fonte: Diário da Justiça Eletrônico - Data: 26/10/2009 - Página: 270 - Ano: 2009. Disponível em: http://trf-5.jusbrasil.com.br/jurisprudencia/8346031/apelacao-civel-ac-411200-al$\underline{0010452-7620054058000}$ acesso em 23 de mar. 2016.

LEITE, José Rubens Morato. Direito ambiental na sociedade de risco. 2.ed. Rio de Janeiro: Forense Universitária, 2004.

MACHADO, Paulo Affonso Leme. Direito Ambiental Brasileiro, 23 ed., rev., ampl., atual. São Paulo: Malheiros Editores, 2015.

MOTTA, Ronaldo Seroa. Manual para valoração econômica de recursos ambientais. Rio de Janeiro. Setembro de 1997. Disponível em: http://www.em.ufop.br/ceamb/petamb/cariboost_files/manual_20serroa_20motta.pdf acesso em 10 Nov. 2014.

PADILHA, Norma Sueli. Fundamentos constitucionais do direito ambiental brasileiro. Rio de Janeiro: Elsevier, 2010.

PAULO, Vicente e outro. Direito Constitucional Descomplicado. 11 ed. Rio de Janeiro: Forense; São Paulo: Método. 2013.

RIO/92, Declaração de Princípios. Declaração do Rio sobre Meio Ambinete e Desenvolvimento. Disponível em: https://pactoglobalcreapr.files.wordpress.com/2010/10/declaracao-do-rio-sobremeio-ambiente.pdf acesso em 29 fev. 2016.

RIVAS, Alexandre. Economia e valoração de serviços ambientais utiliza ndo técnicas de de preferencias declaradas .Manaus, EDUA, 2014.

SILVA, José Afonso da. Direito Ambiental Constitucional. 10 ed., atualizada. São Paulo: Malheiros Editores, 2013. 
SILVA, Romeu Faria Thomé da. Manual de Direito Ambiental. 5aed. Salvador: Editora JusPodivm, 2015.

SIRVINSKAS, Luís Paulo. Manual de direito ambiental. 2.ed.rev.,atual.e ampl. São Paulo: Saraiva, 2003. 